\title{
PRÁTICA DE ENSINO DE CIÊNCIAS: O MUSEU COMO ESPAC̣O FORMATIVO
}

\author{
Daniel Fernando Bovolenta Ovigli*
}

RESUMO: A formação inicial de professores de ciências tem desenvolvido de forma incipiente o tema da educação em museus e centros de ciências. Nesse sentido, este artigo apresenta apontamentos sobre a formação que futuros professores tiveram para atuar em um centro de ciências (CDCC/ USP), suas concepções sobre as características da educação escolar e extra-escolar e as contribuições formativas oferecidas por esse espaço, na perspectiva de compreendê-lo como um lócus formativo na prática de ensino de ciências. Trata-se de uma investigação de natureza qualitativa, com a realização de entrevistas semi-estruturadas com quatro licenciandas-mediadoras, atuantes no centro de ciências mencionado. A inserção do estágio em espaços extra-escolares na prática de ensino também pode configurar-se como alternativa viável para a formação docente em Ciências.

Palavras-chave: Educação em museus; prática de ensino; formação docente.

\section{SCIENCE TEACHING PRACTICE: MUSEUMS AS A TRAINING SPACE}

ABSTRACT: The initial training of science teachers has hardly explored the theme of education in museums and science centers. This paper focused on this theme by investigating future teachers who work at a science center (CDCC/USP), their views on the characteristics of school and extra-school education, and the contributions provided by this space, with a view to recognize it as a training space for science teaching practice. The study used a qualitative approach through semi-structured interviews with four undergraduate-mediators working at the science center in question. Trainee programs at extra-school spaces can also represent a viable alternative to initial training of science teachers.

Keywords: education in museums, teaching practice, teacher training.

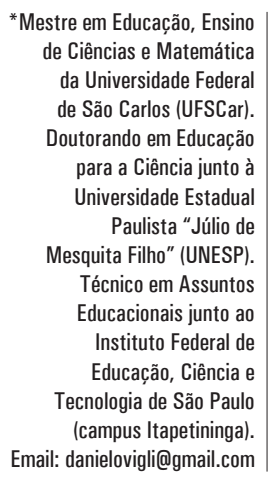

* Mestre em Educação, Ensino de Ciências e Matemática da Universidade Federal de São Carlos (UFSCar).

Doutorando em Educação para a Ciência junto à Universidade Estadual Paulista "Júlio de Mesquita Filho" (UNESP). Técnico em Assuntos Educacionais junto ao Instituto Federal de Educação, Ciência e Tecnologia de São Paulo (campus Itapetininga). Email: danielovigli@gmail.com 


\section{INTRODUCุãO}

A importância do ensino de Ciências Naturais em todos os níveis de escolaridade tem sido objeto de discussão em diversos trabalhos desenvolvidos no Brasil. Embora haja convergência de opiniões quanto à necessidade do ensino de Ciências, o qual já é presente nos currículos e planejamentos escolares, ainda hoje a formação científica oferecida na Educação Básica não é suficiente, se considerarmos como um de seus principais objetivos a compreensão do mundo que nos cerca (CHASSOT, 2003). Trata-se de uma possibilidade de promover a alfabetização científica, de modo que o sujeito da aprendizagem tenha condições de refletir sobre o conhecimento científico de forma a realizar leituras de seu entorno social, no qual este conhecimento se faz cada vez mais necessário. Não sendo mais possível pensar na formação do cidadão crítico à margem do saber científico, a relação educação/sociedade induziu a uma aproximação das Ciências Naturais às Ciências Humanas e Sociais (SNOW, 1995), a fim de reforçar a percepção da Ciência como uma construção humana. Nesse sentido, a Ciência deve ser vista como parte da cultura, tendo o cidadão meios de enriquecimento cultural cientifico para, ao questionar as informações difundidas pela mídia, fazer uma leitura mais consciente da época em que vive.

Nessa perspectiva, diferentes recursos contribuem para o processo de educação científica das pessoas tais como livros, documentários, revistas e material de divulgação científica, entre muitos outros meios. Museus e centros de ciências, no entanto, possuem características bastante particulares que os distinguem de outras instâncias educativas, sejam elas formais, escolares, ou não.

Em um contexto de valorização das vantagens pedagógicas das visitas escolares a museus e centros de ciências, foram criados, nessas instituições, os chamados serviços educativos. Direcionados para o atendimento dos públicos visitantes, inicialmente tais setores contavam com profissionais pouco especializados na função pedagógica. Na maior parte das vezes, as visitas eram conduzidas pelos próprios curadores das exposições, que também eram responsáveis por sua manutenção diária e estudo. Sendo especialistas no assunto da exposição, os curadores enfrentavam desafios para divulgar seu conhecimento ao público. Os professores das escolas, por desconhecerem as especificidades educativas desses locais, limitavam-se ao aproveitamento dos potenciais pedagógicos das coleções dos museus (MARANDINO et al., 2008). Há que se ressaltar que o papel educacional dessas instituições tem se ampliado consideravelmente nas últimas décadas, caracterizando as múltiplas formas pelas quais esses espaços participam da educação científica dos públicos. Com a missão de contribuir para o desenvolvimento dos objetivos educacionais dessas instituições, com freqüência faz-se presente a figura do mediador, que concretiza o diálogo da exposição com o público, recontextualizando o discurso científico para os visitantes (QUEIROZ et al., 2002).

Mais recentemente, são desenvolvidas experiências de inclusão da perspectiva da mediação em espaços como museus e centros de ciências na formação 
inicial do professor nos cursos de licenciatura. Essas iniciativas indicam ser cada vez maior a necessidade de se pensar a formação desse profissional nos aspectos de conteúdos específicos, integrados aos aspectos voltados à educação e à divulgação do conhecimento científico (MARANDINO, 2003).

Este cenário, considerando as possibilidades de aprendizagem que podem acontecer em âmbito extra-escolar, bem como o fato de que tais espaços são contemplados de forma incipiente nos currículos de formação de professores de Ciências, nos levaram a investigar as contribuições formativas desses espaços para os futuros professores e a possibilidade de inserção dos mesmos como espaços para estágio na disciplina Prática de Ensino.

\section{QUADRO TEÓRICO}

A história das disciplinas de Metodologias e/ou Práticas de Ensino no Brasil tem início na década de 1930 e, ao longo de sua existência no currículo, tornou-se parte integrante dos cursos de licenciatura na forma de estágio curricular. Juntamente com o estágio, as práticas de ensino tiveram caráter complementar ou suplementar, aparecendo ao final do curso de formação (MARANDINO, 2003).

Nos últimos anos, este tema da educação em museus tem sido destacado, entre outros fatores, devido à elaboração das diretrizes curriculares para formação docente. As discussões atuais, nesse aspecto, propõem que o professor deve ser visto como um profissional autônomo, que reflete, toma decisões e cria durante sua ação pedagógica, a qual é entendida como um fenômeno complexo, singular, instável e carregado de incertezas e conflitos de valores (MORTIMER e PEREIRA, 1999).

No Brasil, alguns movimentos de se repensar a Prática de Ensino de Ciências e seu papel na formação docente se deram com as Escolas de Verão para professores de Prática de Ensino de Física, de Química e de Biologia, reforçando o enfoque dessas disciplinas não apenas como espaço de vivência pedagógica, mas também de pesquisa. Nesse sentido, o estágio assume especial importância para a formação do licenciando (MARANDINO, 2003).

Frente às diversas limitações que hoje existem quando da realização do estágio na educação básica, se desenvolve uma postura negativa de licenciandos e professores da educação básica sobre essas práticas. Também se questiona se de fato o estágio nesses espaços proporciona vivência pedagógica aos futuros professores. Assim, outros mecanismos têm sido propostos, como a realização de palestras pelos licenciandos, projetos em parceria com a escola básica e atividades de extensão.

Em uma perspectiva diferenciada, o estágio em espaços externos à escola vem sendo estimulado, em um movimento de fortalecimento das instâncias não formais de educação, dentro dos pressupostos que apregoam a necessidade de aprendizagem ao longo da vida, em especial na área científica: daí a relevância que 
museus e centros de ciências assumem ao possibilitar a aproximação ciência/sociedade, considerando que grande parte da população já se encontra fora da escola (MARANDINO, 2003).

No caso dos professores de ciências, a formação deve incluir temas de pesquisa em educação científica e também cabe à metodologia e/ou prática de ensino articular os saberes específicos das ciências com aqueles pertinentes ao campo educacional, considerando questões relativas tanto ao campo educacional como ao campo científico. Nesse sentido, a matriz curricular das licenciaturas deve levar em conta tais discussões, no tocante à interface saberes específicos/ saberes pedagógicos, educação não formal e divulgação científica. Esses diferentes ecossistemas educativos propiciam novos espaço-tempo na produção e difusão de conhecimentos (MARANDINO, 2002).

Museus e centros de ciências, nesse cenário, aparecem como possibilidade de articular espaços não formais com a formação docente, tendo em vista, inclusive, uma possível atuação futura dos licenciandos nesses locais, buscando a ampliação do espectro de atuação desses profissionais. A parceria museu-escola também pode ser favorecida dentro desse modelo de estágio docente, visto que os licenciandos, conhecendo as especificidades educativas que esses espaços apresentam, também podem passar a reconhecer o museu como um espaço educativo e inseri-lo futuramente em sua prática pedagógica, enquanto professores da educação básica. Frente ao aumento do número de centros de divulgação e a mobilização social em torno da alfabetização científica, escolas, universidades e museus podem atuar conjuntamente, partilhando o poder e a responsabilidade de formar e educar. Para Marandino (2003), “a idéia de parceria educativa corresponde a um movimento social de questionamento da distribuição de responsabilidades e poderes, onde se busca compartilhar essas responsabilidades" (p. 64).

Particularmente no que diz respeito à formação inicial do professor de Ciências, experiências educativas realizadas em espaços extra-escolares vêm sendo incentivadas, fundamentadas na ideia de que as exigências educacionais da atual sociedade do conhecimento requerem o fortalecimento de instâncias não formais de educação (FENSHAM, 1999; JENKINS, 1999), da valorização da aprendizagem ao longo da vida, em especial na área científica (YOUNG e GLANFIELD, 1998), e da articulação entre educação formal e não formal (CAZELLI, 2005; VAN-PRÄET e POUCET, 1992).

Desse modo, torna-se fundamental a discussão acerca dos meios pelos quais a divulgação científica vem acontecendo em âmbito extra-escolar e, nesse sentido, a pesquisa na área de educação em Ciências vem crescendo, e os pesquisadores têm consciência de sua importância. Museus e centros de ciências são espaços de grande relevância para as investigações no campo da educação científica, e algumas pesquisas, desenvolvidas no contexto brasileiro, referem-se aos aspectos educativos desses espaços, incluindo, entre eles, o tema da formação e atuação de educadores e monitores de museus e centros de ciências (SOARES, 2003; SILVA, 2009), bem como a inserção da prática de ensino nesses espaços (CARVALHO, 
2009). Assim, os mediadores, educadores desses espaços, ocupam importante papel, visto que são eles que concretizam a comunicação da instituição com o público e propiciam o diálogo com os visitantes acerca das temáticas em exposição, dando-lhes novos significados.

Assim, a universidade - por meio da Licenciatura -, a escola e os museus - ou os centros de cultura científica - constituem importantes parceiros na educação científica e, particularmente, na formação inicial de licenciandos-mediadores. Segundo Queiroz e colaboradores (2002, p.78), "o mediador pode colaborar para tornar uma visita significativa, preenchendo o vazio que muitas vezes existe entre o que foi idealizado e a interpretação dada pelo público do que está exposto”.

\subsection{Museu, Interação e Formação}

Em uma perspectiva vigotskiana, a mediação é um processo de inserção de um elemento intermediário em uma relação, que deixa de ser direta e passa a ser mediada por esse elemento. A mediação se caracteriza, portanto, como a relação que o ser humano estabelece com o mundo e com outros seres humanos e é de fundamental importância, visto que é por meio desse processo que as funções psicológicas superiores (pensamento abstrato, raciocínio dedutivo, capacidade de planejamento, atenção, lembrança voluntária, memorização ativa e controle consciente do comportamento) se desenvolvem. A teoria de Vigotski (1987) também considera dois elementos fundamentais a qualquer processo em que há mediação: o "instrumento", que tem a função de regular as ações sobre os objetos, e o "signo", que regula as ações sobre o psiquismo das pessoas.

O ser humano aprende, de forma que novos conhecimentos são assimilados mais facilmente na interação com outros sujeitos e objetos. A mediação corresponde, portanto, a uma ampliação do entendimento do processo de aprendizagem. Em museus e centros de ciências, "mediar é provocar diálogos entre visitantes e experimentos, interação presencial ou virtual capaz de promover novas aprendizagens nos visitantes" (MORAES et al., 2007, p. 57). Os autores dizem que tais "diálogos" podem ser estimulados pelos mediadores e também pelos experimentos interativos e demais objetos que integram a exposição. Nesse sentido, a mediação se aproxima do sócio-construtivismo, pressupondo interações sociais como forma de potencializar aprendizagens. Para isso, a mediação fundamenta-se no uso intenso de diferentes linguagens, que podem ser faladas ou escritas. "Seja pela fala, seja pela escrita ou por outros modos de mediação semiótica, a linguagem está sempre presente nos processos de mediação" (p. 57). À linguagem é, portanto, atribuído papel fundamental, visto ser ela que possibilita a aproximação do público com a ciência divulgada nos espaços extra-escolares, incentivando os visitantes no desenvolvimento de novas aprendizagens.

Segundo Marandino (2001), a correta compreensão dos conceitos científicos de que trata o museu ou centro de ciências pode realmente acontecer desde 
que as estratégias utilizadas na elaboração da exposição sejam articuladas com a liberdade de leituras e interpretações por parte dos públicos. Para a autora "monitores não são imprescindíveis e as exposições não podem depender deles para serem compreendidas. Por outro lado, talvez seja a mediação humana a melhor forma de obter um aprendizado correto dos conceitos abordados nas exposições” (p. 397).

Reiterando o papel de museus e centros de ciências como locais de aprendizagem, os mediadores, neles, são vistos como parceiros mais capazes, que auxiliam alguém a aprender. Em sua prática diária, são comuns situações em que o mediador necessita improvisar, no local, respostas aos questionamentos do público visitante (seja ele escolar ou espontâneo) que podem incluir concepções alternativas e dúvidas que o mediador talvez não saiba responder (GOMES DA COSTA, 2007). Além de requerer certo aprofundamento no conhecimento científico, a pessoa que realiza a mediação da exposição para o público também necessita de habilidades comunicacionais para chamar o visitante a expor suas concepções para, então, construir a partir delas. Portanto, vários outros saberes são construídos e vão além daquilo que uma formação científica de qualidade pode oferecer. Gomes da Costa (2007) afirma que "são essenciais prática e capacitação específicas para desenvolver a improvisação científica com precisão e as habilidades para dialogar sobre ciência” (p. 31).

Além das habilidades destacadas pelo autor supracitado, Moraes e colaboradores (2007) acrescentam o vocabulário e a adequação de linguagem, considerando os diferentes públicos que visitam museus. Segundo o autor, para que uma mediação seja eficaz é fundamental que o mediador saiba flexibilizar os diálogos e desafios, considerando as idéias trazidas pelo visitante.

Considerando o caráter educativo de um espaço de ciências extra-escolar, a atividade de ensino que se processa nesse espaço se traduz como a mobilização de diversos saberes que constituem a bagagem utilizada pelo docente/mediador para contornar a imprevisibilidade de seu cotidiano profissional. De acordo com Tardif (2002, p. 36), os saberes docentes são constituídos “de vários saberes provenientes de diferentes fontes. Esses saberes são os saberes das disciplinas, os saberes curriculares, os saberes profissionais (compreendendo as ciências da educação e a pedagogia) e os da experiência". Para esse mesmo autor, a prática docente "integra diferentes saberes, com os quais o corpo docente mantém diferentes relações. Pode-se definir o saber docente como um saber plural, formado pelo amálgama, mais ou menos coerente, de saberes oriundos da formação profissional, dos saberes das disciplinas, dos currículos e da experiência” (TARDIF, 2002, p. 36).

Tardif e Lessard (2007) afirmam que o trabalho do professor, nas mais diferentes situações de interação com os estudantes durante as aulas, faz com que os professores construam um repertório de competências e habilidades. "A emoção cognitiva ou interpessoal, a criatividade e outros componentes fortemente ligados à arte trazem para a sala de aula a perspectiva do professor artista-reflexivo, capaz de associar ciência e arte em sua prática” (QUEIROZ et al., 2002, p. 80).

Considerando a importância dos museus de ciências no processo educativo, Chagas (1993) ressalta a importância de os futuros professores terem formação 
para atuar nesse intercâmbio entre o espaço escolar e o extra-escolar. A autora reafirma a necessidade de desenvolver, junto aos professores, habilidades para utilizarem e explorarem os recursos do museu, visando à melhoria da formação científica de seus alunos. Para ela, essa formação pode ser oferecida durante os cursos de formação docente em sua fase inicial ou, ainda, em cursos de formação continuada.

O mediador é, simultaneamente, alguém que ensina, mas que também aprende, em um processo permanente e compartilhado de experiências que ocorrem no cotidiano de seu trabalho. Soares (2003) afirma que essa posição de aprendiz e educador é, na ação de divulgação científica, "estratégica e múltipla, pois diz respeito aos saberes e fazeres que estes profissionais de museus necessitam articular a fim de dar qualidade aos seus desempenhos" (p. 83). Para Soares, um mediador dito "experiente" tem a capacidade de articular seus "saberes e fazeres numa dinâmica, muitas vezes própria, que garante a qualidade na execução dos objetivos estabelecidos para uma exposição".

Queiroz e colaboradores (2002) destacam que ações direcionadas à melhoria da relação museu-escola podem e necessitam ser implementadas e analisadas, também visando ao desenvolvimento de um trabalho mais intenso na formação docente "para a participação como mediadores em ações de alfabetização científica que incluam museus e centros de ciências" (p. 79). Marandino (2001) destaca que a formação dos professores para que possam utilizar mais eficazmente museus e centros de ciências é uma preocupação em âmbito internacional, evidenciando a necessidade desse processo na saída da escola para o museu. E completa:

\footnotetext{
[...] deve-se levar em conta a história e a especificidade pedagógica dos museus para otimizar as visitas escolares. A formação de professores deverá contemplar não só elementos descritivos das exposições, mas também a perspectiva de compreensão do que seria uma pedagogia particular de museu. Assim, não se trata de opor o museu à escola, mas de analisar, objetivando o aprimoramento, as especificidades das exposições e das ações culturais no museu. Esta matriz de especificidades relacionadas ao lugar, ao tempo e aos objetos no espaço do museu é essencial e deve ser incluída na formação de educadores numa didática de museu (p. 3).
}

Portanto, é no campo da formação docente em ciências que se pretende investigar as possíveis contribuições desse espaço para a formação inicial de professores de ciências. Assim, a questão de pesquisa assumiu o seguinte enfoque: "Como mediadores-licenciandos de um centro de ciências atribuem significado ao estágio nesse espaço para sua formação docente inicial?”

\section{METODOLOGIA}

A perspectiva de pesquisa assumida para o desenvolvimento desta investigação é de natureza qualitativa, pois, segundo Minayo (1994), busca trabalhar com o universo de significados, motivações, crenças, valores e atitudes, 
correspondentes a um espaço mais profundo das relações, dos processos e dos fenômenos ocorrentes na pesquisa de campo.

Para alcançar os objetivos propostos, foram realizadas entrevistas com quatro licenciandos-mediadores que atuam nas exposições de Ciências (Física e Biologia) do Centro de Divulgação Científica e Cultural (CDCC), órgão de extensão da Universidade de São Paulo (USP), campus São Carlos, estado de São Paulo. Esses licenciandos-mediadores são alunos do último ano de um curso de licenciatura na área de ciências oferecido pela USP e aqui serão denominados A, B, C e D. Os dados obtidos foram tratados pela análise de conteúdo. Do ponto de vista analítico, a análise de conteúdo mostra-se como um elemento para a compreensão dos dados obtidos com a realização das entrevistas (FRANCO, 2005). Neste trabalho, em especial, o objetivo de sua utilização é efetuar deduções lógicas e justificadas, referentes à origem das mensagens em estudo, bem como explicitar e sistematizar tal conteúdo à luz dos referenciais teóricos que abordam a formação e os saberes docentes, adequando-o às situações ocorrentes no centro de ciências investigado. À época da realização da entrevista, todos os sujeitos iniciavam a disciplina Prática de Ensino de Ciências. Há que se ressaltar que, naquele momento, o estágio no CDCC/USP não havia sido descrito como parte integrante das atividades a serem desenvolvidas na disciplina Prática de Ensino. Dessa forma, os sujeitos investigados faziam parte do quadro regular de mediadores da instituição.

\section{RESULTADOS E DISCUSSÃO}

\subsection{A formação na licenciatura para atuação no centro de ciências}

Os licenciandos-mediadores relatam que espaços educativos extra-escolares, com enfoque de futura utilização por eles em sua prática pedagógica, não foram estudados em sua formação inicial, nas disciplinas da graduação.

"Em nenhum momento a gente fala em utilizar museus ou centros de ciências, lógico que como forma de ser... de dar aula... de ser um espaço de educação (...) nunca surgiu do professor essa idéia, de que espaço de educação não é só a escola, podem ser outros lugares, isso até agora não apareceu”. (Mediadora B)

Iniciativas de inserção de atividades de mediação em espaços extra-escolares apontam para a necessidade premente de se refletir sobre a formação docente no que diz respeito aos conteúdos específicos, integrados aos estudos que enfocam a divulgação do conhecimento científico. Na atualidade, defende-se que a formação do professor seja desenvolvida por meio da reflexão, em uma relação na qual a prática se vale da teoria e viceversa, originando uma prática ressignificada (MORTIMER e PEREIRA, 1999), o que também é possível em um contexto não formal. É nesse sentido que o conhecimento profissional do professor também é construído quando do desenvolvimento de estudos 
e estágios em ambiente extra-escolar, particularmente um centro de ciências.

Shulman (1986) relata a escassez de trabalhos que reflitam sobre a articulação conhecimento pedagógico/conhecimento específico. Essa constatação também se faz presente na fala de nossos entrevistados, ainda quando questionados sobre a formação que tiveram para atuar no centro de ciências.

"Não, essa pode ser uma fonte pra você trazer seus alunos. Nesse sentido, não!" (Mediadora C)

Para a monitora B "em nenhum momento ele [o professor de disciplina da graduação] falava "Ó, quando vocês forem dar aula façam de tal jeito, tem que ter tal postura", não!". Da mesma forma, para a monitora 1 esse assunto "não foi tratado em sala de aula".

No entanto, os professores responsáveis pelas disciplinas da graduação, em especial aqueles responsáveis por ministrarem disciplinas específicas, segundo as monitoras, fizeram uso esporádico de atividades de campo e visitas a museus e centros de ciências, embora nem sempre houvesse clareza no enfoque pedagógico de utilização dessas atividades.

"Teve algumas que a gente foi relacionado à Biologia (...) eu entendo isso como uma viagem em que você passa por um espaço não formal. A gente foi na Estação Ciência e a gente foi também... teve bastante eventos no Ibirapuera. Teve viagem didática bem legal que a gente fez em Biologia, a gente ia lá, tinha explicação, olhava a folha, os animais. Então a gente via muito do que aprendeu em Biologia II”. (Mediadora A)

"A gente teve viagens pedagógicas, a gente foi pra Ilha do Cardoso, foi pro Zoológico, foi pro Jardim Botânico com a professora de Biologia, foi pra parte de Astronomia”. (Mediadora B)

Segundo Zeichner (1993), a formação docente na perspectiva da reflexão tem enfocado mais intensamente as maneiras de incentivar os futuros professores a pensarem sobre seus métodos de ensino, do que para questionarem as finalidades educativas que buscam alcançar com seus alunos. De acordo com esse autor, a visão dos licenciandos sobre sua formação recai sobre aquela que ele intitula acadêmica, que enfatiza os conteúdos conceituais da disciplina a ser ensinada, nesse caso, as Ciências da Natureza. Há que se ressaltar que dificilmente se tem uma formação estritamente acadêmica; outras abordagens formativas também podem estar presentes, embora em menor grau, em especial a vertente reflexiva, que também possibilita a tomada de consciência sobre o processo vivenciado.

“(...) isso que vocês tão vendo agora, essa viagem vocês podem usar quando vocês quiserem explicar tal coisa pros seus alunos, levem ao Jardim Botânico, levem ao CEU em Brotas pra explicar Astronomia", Não, não tinha essa reflexão". (Mediadora D)

Segundo a fala da licencianda-mediadora D, a inserção das atividades extraescolares pelos professores da graduação foram estratégias recorrentes, em especial 
nas disciplinas de Física e Biologia. Mesmo que, por vezes, os espaços visitados pelas licenciandas possibilitassem a participação de alunos da Educação Básica em suas atividades, os professores da universidade não mencionavam tal possibilidade.

\subsection{A educação escolar e a educação em centros de ciências}

Esta categoria traz as concepções dos sujeitos investigados sobre a educação que se processa em centros de ciências e a educação que ocorre na escola. Competências e habilidades necessárias à atuação na escola são elencadas pelas licenciandas-mediadoras como também necessárias à atuação no centro de ciências, embora este apresente certas especificidades.

"(...) aqui [o centro de ciências] a gente fala que é um complemento à sala de aula, mas não é sala de aula". (Mediadora C)

Guimarães e Vasconcellos (2006) dizem que é preciso entender que escola e centro de ciências possuem funções sociais diferentes e particularidades. Essa advertência é importante para que não se submeta a educação extra-escolar aos referenciais estritamente escolares e vice-versa. Assim, não deve ser cobrado das atividades no museu um aprendizado formal. Isso comprometeria a motivação e a aprendizagem significativa, quando esta ocorre a partir de relações que se estabelecem entre idéias já existentes, confrontadas com novas experiências no museu e que objetivam construir novas idéias. A fala da mediadora $C$ corrobora essa afirmação:

Lá [sala de aula] a minha função em sala de aula é passar conhecimento, falar que $f=m a$. Aqui minha função é tentar faz̧er o visitante deduzir aquilo. Eu nunca posso falar pra ele que $f=m a$. Eu posso falar o que "Ah, você tá sentindo, é uma força. Tá, pra que que depende essa força?" Ele tem que ver que depende da massa e da aceleração, mas eu não posso falar isso pra ele". (Mediadora C)

O caráter de não formalidade das instituições museais também permite uma maior liberdade na seleção e organização de conteúdos e metodologias, o que amplia as possibilidades de interdisciplinaridade e contextualização, bem como atualização frente ao currículo praticado nas escolas (Vieira et al., 2005; Gaspar, 1993). Por esse motivo, elas possuem um grande potencial para promover a motivação para o estudo e aprendizado das Ciências (Falk e Dierking, 2002), como destaca a mediadora B.

“(...) eu acho que eles preferem aqui. Uma coisa que eu acho também que acontece é que distrai eles, a atenção deles foge um pouco. Você vir pro museu e ir pra uma visita a campo, o mosquitinho, a árvore, água, o que eles veem. (...) Mas o legal é essa percep̧̧ão que eles têm, de ver aqui o que eles nunca viram".

Segundo a mediadora B, a experiência vivenciada em um espaço como 
esse proporciona aos públicos experiências que dificilmente poderiam ser reproduzidas em outros contextos (quando a mediadora utiliza a expressão "nunca viram”), como a percepção de odores, sons e texturas, aproximando-os de uma dimensão também lúdica. Nesse sentido, museus e centros de ciências valorizam não apenas a "formação racional e intelectual do indivíduo, mas considera sua dimensão emocional” (PEREIRA, 2005, p. 100).

\subsection{Competências e habilidades necessárias à atuação do mediador}

A análise de conteúdo possibilitou o levantamento de algumas categorias comuns às falas dos sujeitos. A contextualização dos conceitos abordados durante a exposição e a capacidade comunicativa são duas habilidades fundamentais à mediação no centro de ciências, recorrentes na fala dos licenciandos-mediadores, que também expressam a possibilidade de utilizar tais elementos em sua prática em sala de aula. Além disso, quanto à interface graduação/atuação no museu, concordam que os conteúdos específicos estudados durante a graduação contribuíram para sua atuação no centro de ciências, sendo para eles fundamental conhecerem bem os conceitos científicos presentes na exposição.

"Eu acho que acima de tudo ele tem que estar bem craque no conceito que ele vai falar, do que ele vai trabalhar e ele precisa se informar bastante sobre questões que se relacionam àquilo que está exposto, pra depois ter informações a mais pra passar, trazer pro cotidiano, contextualizar os temas, abordar curiosidades (....)". (Mediadora A)

O desenvolvimento de competências comunicativas, segundo os sujeitos da investigação, se deu parcialmente durante a graduação, em disciplinas que incluÍam a realização de seminários e outras apresentações orais, em especial nas disciplinas pedagógicas. A prática da comunicação pode ser complementada durante a mediação nas exposições, ilustrado pela fala da mediadora C:

"Seminário também foi uma coisa que eu aprendi a fazer, tinha muito medo (...) hoje apresento totalmente diferente, meu jeito de falar, meu medo de me expor na frente. Eu acho também que está relacionado com o meu trabalho".

Para ela, a atuação no CDCC contribuiu em grande medida para o desenvolvimento de suas habilidades comunicativas, o que se refletiu inclusive na graduação, quando da necessidade de realizar apresentações orais.

Os espaços extra-escolares de educação científica possibilitam que os mediadores que nele atuam ocupem um papel de grande importância, pois são eles que efetivamente realizam a comunicação da exposição com o público e possibilitam o diálogo com o público sobre as questões abordadas no centro de ciências, ressignificando os objetos expositivos. Há que se considerar as diferen- 
tes faixas etárias do público visitante, o que também é fundamental conhecer para que a mediação seja mais eficaz. Para a mediadora D:

"Eu acho também a articulação da linguagem, eu acho de fundamental importância. Ter essa linguagem. Mesmo porque o público que vem é muito diferente, são niveis diversificados..."

Por vezes as atividades de mediação no centro de ciências se expressam como uma forma de vivenciar situações protagonizadas por professores da Educação Básica, espelhando futuras ações a serem por eles desempenhadas na Educação Básica.

"Eu sou muito comunicativa, eu falo muito e bom... acho que gosto dessa posição de estar à frente de uma sala falando alguma coisa pra alguém, gosto dessa imagem mesmo da professora, sabe? De estar na frente de pessoas e falando alguma coisa". (Mediadora B)

\subsection{A experiência formativa proporcionada pela atividade de mediação no centro de ciências}

A dimensão reflexiva apresenta-se nas situações imprevisíveis e na necessidade de procurar encaminhamentos para situações inesperadas, tentando desenvolver uma mediação mais eficaz. A esse respeito Pérez Gómez (1992), partilhando das idéias de Schön, descreve a realidade do professor como aquele que intervém em um meio ecológico complexo, em um cenário vivo e mutável. Nessa realidade o professor enfrenta problemas singulares. O êxito do profissional, como destaca o autor, depende da sua capacidade de manejar a complexidade e resolver problemas práticos, por meio da integração inteligente e criativa do conhecimento e da técnica (YINGER, 1986 apud PÉREZ GÓMEZ, 1992), questões pertinentes àquelas protagonizadas por monitores de museus de ciências.

"Como eu trabalho como monitora, principalmente na parte de como me expressar, perceber se a pessoa realmente está entendendo, ter um jogo de cintura pra tentar sair, vejo se a pessoa não está entendendo, tento arranjar outros meios para explicar de um jeito que a pessoa entenda o que eu quero passar". (Mediadora A)

Há coerência com as ideias de Tardif (2002). Para esse autor, os saberes são delineados pela competência do docente em agir de acordo com contextos de ação de grande complexidade, situação que também acontece em ambiente extra-escolar.

Durante a ação, o mediador passa por diferentes situações-problema, como conflitos, dúvidas, desinteresse do grupo ou de algum visitante específico, entre outras. Para solucioná-las ele reflete sobre as vivências e experiências adquiridas e, na própria ação, toma uma decisão (nem precisando verbalizá-la). Assim, uma visita monitorada, considerada como processo de formação, constitui-se essencialmente de tomadas de decisão, mesmo que para esse mediador essas não sejam tão claras e conscientes (MARANDINO, 2008, p.29). 
A esse respeito revelam as monitoras:

'Um monitor ele tem que ser muito eclético, ter uma percepção muito ampla. Por quê? Porque a gente tem que saber olhar pro visitante e saber o perfil dele, saber se ele é uma pessoa que gosta só de ler, gosta dele descobrir as coisas, então você tem que ter a sensibilidade de falar "Não vou nem ficar perto porque senão vou atrapalhar!" Ou então "Não, ele é um visitante que quer que eu fique falando e mostrando e lendo, levando ele até as atividades", então acho que o perfil do monitor, o principal, é que o monitor hoje tem que ter sensibilidade de você olhar o visitante e saber o que ele quer". (Mediadora B)

"Ele deve ter um pouco da sacada, um jogo de cintura pra saber que momento ele deve interferir (ou não) na mediação, na pergunta. Porque o certo seria a gente, só através de questões, despertar o aluno para que ele responda, então a gente teria que fica jogando questões. Tá, mas e aí, e agora? Se eu colocar isso ali o que acontece?" (Mediadora A)

Assim, em virtude das imprevisibilidades da prática, o mediador de museus trabalha na perspectiva da reflexão-na-ação, ao lidar com tais situações por meio da inteligência e da improvisação.

Ao considerarmos o museu ou centro de ciências um espaço formativo, tanto para aprendizagem das Ciências da Natureza como também da docência, há possibilidade de transformá-lo em um lugar de grande importância para a formação de professores desde a sua fase inicial, avançando nas formas pelas quais essta instituição tem sido tradicionalmente utilizada. Mediante parcerias com a universidade, torna-se possível uma reconstrução reflexiva dos pressupostos didáticos trazidos pelos futuros professores.

"Essa sensibilidade de conhecer as pessoas e saber como eu posso falar o mesmo conteúdo de várias formas, eu só consegui aqui, se eu não tivesse passado por aqui, se eu não tivesse trabalhado (...) será que eu sei explicar? Eu falo, será que as pessoas entendem o que eu falo? (...) Será que eu sei conteúdo suficiente pra poder explicar pra uma pessoa? Então acho que essa experiência só consegui porque eu tava trabalhando aqui (...) São coisas que eu acho que eu tô um pouco mais tranquila”. (Mediadora C)

A dimensão reflexiva apresenta-se nas situações imprevisíveis e na necessidade de procurar encaminhamentos para situações inesperadas, tentando desenvolver uma mediação mais eficaz, o que torna possível o desenvolvimento de competências e habilidades por parte das mediadoras.

Schön (1992) afirma que o conhecimento profissional do professor vai sendo delineado pela competência do docente em agir de acordo com contextos de ação de grande complexidade, situação que também acontece em ambiente extra-escolar. As diferentes situações-problema a que o mediador está submetido em seu trabalho cotidiano exigem que ele reflita sobre as vivências e experiências construídas e, na própria ação, tome uma decisão que conduza à solução da situa- 
ção. Os mediadores, assim como os professores na escola, constroem um repertório de conhecimentos que lhes possibilita teorizar sobre a própria mediação.

"Dai você tem que analisar no que ele tá interessado. Se ele tá... por exemplo, ele trouxe um MP5, não pára de mexer naquele MP5, quer ficar sentado para ficar brincando com o MP5 dele. "Você começa a conversar alguma coisa do MP5 que tem aqui no museu, por exemplo: você sabe como isso funciona? Você tá ouvindo música, você sabe o que é o som? Você sabia que o som é uma onda?", por exemplo. Daí você começa a atrai-lo para alguma coisa que tem aqui e que chame a atenção dele".

"O contato com o público, saber me expressar melhor, como atrair a atenção (...) você vê "Ah eu posso explicar isso de tal forma na escola!” (Mediadora C)

Sendo o centro de ciências um espaço formativo que também contempla o paradigma reflexivo, faz-se necessário ressignificá-lo como um local de relevância na formação inicial docente, instrumentalizando o futuro professor nas vertentes racionais, estéticas, técnicas e emocionais, dada a imprevisibilidade do fenômeno educativo, também ocorrente em espaço extra-escolar. Algumas dessas habilidades são, inclusive, compartilhadas com a instituição escolar.

Há, por fim, que se considerar a dimensão da reflexão sobre a reflexão-na-ação. Assim como o professor após a aula, o mediador pode pensar no que aconteceu durante uma visita, no significado que atribui à visita naquele momento e na eventual adoção de outros sentidos. Os mediadores de museus, ao analisarem suas práticas, registrando por escrito suas percepções e/ou discutindo com a coordenação educacional do centro de ciências, certamente refletirão sobre seu fazer cotidiano. Assim, a reflexão-na-ação é uma estratégia pedagógica que concorre para a construção e a melhoria da prática da mediação humana em museus e deve ser incentivada e investigada, conforme já apontado por Moraes e colaboradores (2008).

\section{ALGUMAS CONSIDERAÇÕES}

Neste momento, tecemos algumas considerações sobre as experiências de mediação que aqui foram analisadas. Para a universidade, a atuação dos licenciandos no museu não é uma atividade consensual, visto que a escola básica, em particular aquela pertencente à esfera pública, é tida como espaço fundamental para a formação docente. Nesse sentido tem sido reiterada a valorização do estágio na Educação Básica como componente essencial na formação docente, pois é por meio dessa experiência que o licenciando iniciará o desenvolvimento de competências e habilidades para sua futura prática pedagógica. Por vezes, esse enfoque conduz ao entendimento de que a educação formal, na sala de aula, é o espaço privilegiado e até único da prática pedagógica.

Em estudos realizados por Fensham (1999), o conhecimento que o pú- 
blico adulto tem sobre temas científicos provém, em grande medida, da ação da divulgação científica, que inclui os centros de ciências. Acreditamos que as parcerias entre museu, escola e universidade configuram-se como estratégias para possibilitar à população o acesso aos conhecimentos científicos. Dessa forma, a formação inicial de professores de ciências não deve prescindir de experiências proporcionadas pelos espaços extra-escolares, também por meio de estágios curriculares integrados à prática de ensino, embora a legislação atual não permita o desenvolvimento dessas ações, ainda que parcialmente, fora da instituição escolar.

Em sua missão, o museu desenvolve ações científicas, culturais e educativas, tornando-se, assim, um espaço privilegiado para o envolvimento dos cursos de formação docente, reforçando a componente educacional que a referida instituição vem assumindo na atualidade. Os dados aqui apresentados corroboram a dimensão formativa que o estágio em um centro de ciências pode proporcionar a licenciandos em ciências, haja vista as competências e habilidades mencionadas pelos sujeitos e que puderam ser observadas quando o pesquisador acompanhou algumas visitas. Há que se considerar que os licenciandos integrantes da amostra deste estudo são bolsistas e cumprem uma carga horária semanal que não lhes é contabilizada como estágio curricular no curso de licenciatura.

Nesse sentido, outros espaços educativos externos à escola precisam ser ampliados e melhor estudados no que diz respeito à educação científica. Concordamos com Marandino (2003), pois

\footnotetext{
Não se trata, assim, de negar o papel crucial que a escola possui na formação do professor, mas sim de compreender que ser profissional professor hoje engloba também o profundo conhecimento das diferentes práticas pedagógicas desenvolvidas em outros espaços educativos como, por exemplo, os museus de ciências (p. 72).
}

Outra questão que merece ser melhor investigada refere-se à consolidação de parcerias museu de ciências/escolas, formalmente encarregadas dos processos educativos. Nesse sentido, o professor de ciências que apresenta uma experiência em espaço extra-escolar pode contribuir, tendo em vista o estabelecimento de uma fecunda relação entre as duas instituições.

Por fim, acreditamos que o estágio em espaços extra-escolares configurase como uma ferramenta potencialmente formativa para licenciandos em ciências. Assim, a parceria universidade/escola/centro de ciências apresenta um caminho que pode favorecer mudanças visando à melhoria da educação científica no Brasil.

\section{REFERÊNCIAS}

CARVALHO, M. A. Um estudo sobre a inserção de atividades em educação não formal na disciplina metodologia e prática do ensino de física da Universidade Estadual de Londrina. 2009. 138 f. Dissertação (Mestrado em Ensino de Ciências e Educação Matemática) - Universidade Estadual de Londrina, Londrina, 2009. CAZELLI, S. Ciência, cultura, museus, jovens e escolas: quais as relações? 2005. 260 f. Tese (Doutorado em Educação) - Departamento de Educação, Pontifícia Universidade Católica do Rio de Janeiro, 2005. 
CHAGAS, I. Aprendizagem não formal/formal das ciências: relações entre os museus de ciência e as escolas. Revista de Educação: Departamento de Educação da Faculdade de Ciências da Universidade de Lisboa, Lisboa, v. 3, n. 1, p. 51-59, 1993.

CHASSOT, A. Alfabetização científica: uma possibilidade para a inclusão social. Revista Brasileira de Educação, v. 22, p. 89 - 100, 2003. Retirado em 12/09/2008, no World Wide Web: http:/ /www.scielo. $\mathrm{br} / \mathrm{pdf} / \mathrm{rbedu} / \mathrm{n} 22 / \mathrm{n} 22 \mathrm{a} 09$.pdf.

FALK, J. H.; DIERKING, L. D. Lessons Without Limit - how free-choice learning is transforming education. California: Altamira Press, 191 p, 2002.

FENSHAM, P. School science and public understanding of science. International Journal of Science Education, v.21, n.7, p. 755-763, 1999.

FRANCO, M. L. B. Análise de Conteúdo. Brasília: Liber Livro, 1999.

GASPAR, A. Museus e centros de Ciências: conceituação e proposta de um referencial teórico. São Paulo, 1993. 173 f. Tese (Doutorado em Educação) - Faculdade de Educação da Universidade de São Paulo, 1993.

GOMES da COSTA, A. Os "explicadores" devem explicar? In: MASSARANI, L.; MERZAGORA, M.; RODARI, P. (Orgs.). Diálogos \& Ciência: mediação em museus e centros de ciência. - Rio de Janeiro: Casa de Oswaldo Cruz/Fiocruz. p. 28 - 31, 2007.

GUIMARÃES, M.; VASCONCELLOS, M.M.N. Relações entre educação ambiental e educação em ciências na complementaridade dos espaços formais e não formais de educação. Educar em Revista, n.27, p.147-162, 2006.

JENKINS, E.W. School science, citizenship and the public understanding of science. International Journal of Science Education, v.21, n.7, p. 703 - 710, 1999.

MARANDINO, M. (Org.). Educação em museus: a mediação em foco. São Paulo: Grupo de Estudo e Pesquisa em Educação Não-formal e Divulgação em Ciências, 2008.

A Biologia nos Museus de Ciência: a questão dos textos em bioexposições. Ciência \& Educação, Bauru, v.8, n.2, p. 187-202, 2002.

. A formação inicial de professores e os museus de Ciências. In: SELLES, Sandra E. e FER-

REIRA, Márcia S. (Orgs.). Formação docente em Ciências: memórias e práticas. (p. 59-76). Rio de Janeiro: EdUFF, 2003.

. O conbecimento biológico nas exposições de museus de ciências: análise do processo de construção do discurso expositivo. 2001. 451 f. Tese (Doutorado em Educação) - Faculdade de Educação, Universidade de São Paulo, São Paulo, 2001.

MORAES, R.; BERTOLETTI, J.; BERTOLETTI; A.; ALMEIDA, L. Mediação em museus e centros de ciências: o caso do Museu de Ciências e Tecnologia da PUCRS. In: MASSARANI, L.; MERZAGORA, M.; RODARI, P. (Orgs.). Diálogos \& Ciência: mediação em museus e centros de ciência. - Rio de Janeiro: Casa de Oswaldo Cruz/Fiocruz, p. 56 - 67, 2007.

MORTIMER, E.F.; PEREIRA, J.E.D. Uma proposta para as 300 horas de prática de ensino - Repensando a licenciatura para além da racionalidade técnica. Educação em Revista, n.30, p. 107 - 113, 1999.

PEREIRA, J. E. A importância do lúdico na formação de educadores: uma pesquisa na ação do Museu da Educação e do Brinquedo - MEB da Faculdade de Educação da USP. São Paulo. 231 f. Dissertação (Mestrado em Educação) - Faculdade de Educação da Universidade de São Paulo, 2005.

PÉREZ GÓMEZ, A. O pensamento prático do professor - a formação do professor como profissional reflexivo. In: Nóvoa, A. (Coord.). Os professores e a sua formação. Lisboa: Dom Quixote, p. 93-114, 1992.

QUEIROZ, G.; KRAPAS, S.; VALENTE, M. E.; DAVID, E.; DAMAS, E.; FREIRE, F. Construindo saberes da mediação na educação em museus de ciências: o caso dos mediadores do Museu de Astronomia e Ciências Afins/Brasil. Revista Brasileira de Pesquisa em Educação em Ciências. v. 2, n. 2, p. 77-88, 2002. SCHÖN, D. Formar Professores como Profissionais Reflexivos. In: Nóvoa, A. Os Professores e a sua Formação. Lisboa: D. Quixote, p. 77 - 92, 1992.

SILVA, C. S. Formação e atuação de monitores de visitas escolares de um centro de ciências: saberes e prática reflexiva. 2009. 151 f. Dissertação (Mestrado em Educação para a Ciência) - Faculdade de Ciências, Universidade Estadual Paulista "Júlio de Mesquita Filho", Bauru, 2009.

SNOW, C. P. As duas culturas e uma segunda leitura: uma versão ampliada das duas culturas e a revolução 
científica. São Paulo: EDUSP, 1995.

SOARES, J. M. Saberes da Mediação Humana em Museus de Ciência e Tecnologia. 2003. 126 f. Dissertação (Mestrado em Educação) - Faculdade de Educação, Universidade Federal Fluminense, Niterói, 2003. SHULMAN, L. Those who understand: Knowledge growth in teaching. Educational Researcher, Washington, v.15, n. 2, p. 4-14, 1986.

TARDIF, M. Saberes docentes e formação profissional. Petrópolis: Vozes, 325 p, 2002.

TARDIF, M.; LESSARD, C. O trabalho docente: elementos para uma teoria da docência como profissão de interações humanas. Petrópolis: Vozes, 317 p, 2007.

VAN-PRÄET, M.; POUCET, B. Les musées, lieux de contre-éducation et de partenariat avec l'école. Éducation \& Pédagogies, n.16, p. 22-29, 1992.

VIEIRA, V.; BIANCONI, M. L.; DIAS, M. Espaços não-formais de ensino e o currículo de ciências. Ciência e Cultura, Out/Dez, v.57, n.4, p. 21-23, 2005.

VIGOTSKI, L. S. Pensamento e Linguagem. São Paulo: Martins Fontes, 159 p, 1987.

YOUNG, M.; GLANFIELD, K. Science in post-compulsory education: towards a framework for a curriculum of the future. Studies in Science Education, v.32, p. 1-20, 1998.

ZEICHNER, K. A formação reflexiva de professores: idéias e práticas. Lisboa: Educa, 1993.

Data de Recebimento: 02/04/2010

Data de Aprovação: 21/09/2011

Data da Versão Final: 26/10/2011 
